\title{
Use of the urinary trypsinogen-2 dipstick test in early diagnosis of pancreatitis after endoscopic retrograde cholangiopancreatography (ERCP)
}

\author{
Hasan El-Garem ${ }^{1}$, Enas Hamdy ${ }^{2}$, Sherif Hamdy ${ }^{1}$, Mohammad El-Sayed ${ }^{1 *}$, Aisha Elsharkawy ${ }^{1}$, \\ Azmi Mohammed Saleh ${ }^{1}$ \\ ${ }^{1}$ Department of Endemic Medicine and Hepatology, Faculty of Medicine, Cairo University, Cairo, Egypt \\ ${ }^{2}$ Department of Clinical Pathology, Faculty of Medicine, Cairo University, Cairo, Egypt \\ Email: ${ }^{*}$ mohammadelsayed76@yahoo.com \\ Received 20 August 2013; revised 25 September 2013; accepted 6 October 2013 \\ Copyright (C) 2013 Hasan El-Garem et al. This is an open access article distributed under the Creative Commons Attribution License, \\ which permits unrestricted use, distribution, and reproduction in any medium, provided the original work is properly cited.
}

\begin{abstract}
Background: Acute pancreatitis is one of the most serious complications of ERCP. Early diagnosis of post ERCP pancreatitis helps physicians to provide intensive care and possible medical treatment as early as possible. Trypsinogen-2 in urine is a good diagnostic and prognostic marker of acute pancreatitis. Objectives: To evaluate the diagnostic value of urinary trypsinogen-2 dipstick test for early diagnosis of post ERCP pancreatitis. Methods: A total of 37 patients with obstructive jaundice were tested with the urinary trypsinogen-2 dipstick test and serum levels of amylase and lipase before ERCP and 6 hours after ERCP. Results: Post ERCP pancreatitis was diagnosed in $6(16 \%)$ of 37 patients. The sensitivity, specificity, positive predictive value and negative predictive value of urinary trypsinogen-2 dipstick test at 6 hours after ERCP were $100 \%, 97 \%, 86 \%, 100 \%$ respectively. At the cutoff level (130 U/L) for lipase, the positive predictive value and negative predictive value all were $(100 \%)$, however, the positive predictive value and negative predictive value for amylase levels at cutoff $(122 \mathrm{U} / \mathrm{L})$ were $60 \%, 100 \%$ respectively. Serum lipase level was the best test for diagnosing post ERCP pancreatitis followed by the urinary trypsinogen-2 dipstick test. Conclusions: The urinary trypsinogen-2 dipstick test can be used as a rapid and easy test for early diagnosis of post ERCP pancreatitis with high sensitivity and specificity.
\end{abstract}

Keywords: ERCP; Pancreatitis; Urinary Trypsinogen-2 Dipstick Test

${ }^{*}$ Corresponding author.

\section{INTRODUCTION}

Since its first reported application in 1968, endoscopic retrograde cholangiopancreatography (ERCP) has become a valuable procedure for examination and treatment of pancreaticobiliary diseases [1]. One of the most serious complications of (ERCP) is acute pancreatitis. The reported incidence varies from $1.3 \%$ to $24.4 \%$ [2]. Measurement of serum amylase and lipase levels after the procedure may have a possible role for early recognition of post-ERCP pancreatitis [3]. Asymptomatic elevation in serum amylase and lipase activities after ERCP is common, occurring in approximately $25 \%$ to $75 \%$ of all patients, owing to the lack of specificity of pancreatic enzymes [4]. Reports indicate that serum and urinary trypsinogen-2 concentrations increase in patients with acute pancreatitis and that trypsinogen-2 levels can serve as a more sensitive diagnostic marker for pancreatitis relative to amylase or lipase [1,5]. A rapid test strip has been developed for the detection of trypsinogen-2 in urine (The urinary trypsinogen-2 dipstick test-UT2DSTactim pancreatitis) which is based on the immunochromatography principle and shows a good sensitivity and specificity in diagnosing acute pancreatitis [6].

The aim of this study was to evaluate the diagnostic value of urinary trypsinogen-2 dipstick test for early diagnosis of post-ERCP pancreatitis.

\section{PATIENTS AND METHODS}

Thirty seven adult patients with obstructive jaundice were referred to Kasr El-Aini Endoscopy Unit to perform ERCP.

\subsection{Inclusion Criteria}

1) Adult patients above 18 years. 
2) Patients having biliary obstruction as diagnosed by elevated serum bilirubin and abdominal imaging showing biliary obstruction.

\subsection{Exclusion Criteria}

1) Pancreatitis within 60 days of ERCP.

2) History of drug that may lead to acute pancreatitis.

3) Age less than 18 years.

4) Pregnant patients.

5) Known renal disease.

6) Known acute pancreatitis.

7) History of pancreatic/biliary surgery.

After an informed consent by the patients the selected patients were subjected to:

Full clinical assessment (history taking and clinical examination), laboratory investigations including (complete blood count (CBC), Bilirubin (total and direct), (ALT), (AST), alkaline phosphatase (ALP), Prothrombin time and concentration (PT \& PC), urea, creatinine, serum amylase, serum lipase, urinary trypsinogen-2 dipstick test (UT2DST).

\section{SPECIMEN COLLECTION}

Two samples of $5 \mathrm{ml}$ fasting venous blood were collected one before \& the other 6 hours after ERCP for each patient, the samples were left to clot and then centrifuged at $3000 \mathrm{rpm}$ for 5 minutes. The serum was then separated \& stored at $-20^{\circ} \mathrm{C}$ for measuring amylase and lipase. Two Urine samples were taken one before \& the other 6hours after ERCP for trypsinogen-2 determination by UT2-DST.

\subsection{Principle of UT2DST}

The Actim ${ }^{\circ}$ pancreatitis dipstick (MedixBiochemica, Kauniainen, Finland) strip, an immunochromatographic test, was used for urine trypsinogen-2 determination (detection limit $50 \mu \mathrm{g} / \mathrm{L}$ ). The tip of the strip was immersed into a urine-containing vial and was held for 20 seconds before being completely taken out of the vial. The strip was then kept at room temperature for 5 minutes to observe whether urine reacted with blue latex particles covered by monoclonal antitrypsinogen- 2 antibodies. Excess $(>50 \mu \mathrm{g} / \mathrm{L})$ urinary trypsinogen-2 caused the occurrence of 2 blue stripes (one for trypsinogen- 2 \& the other as control), while only one stripe (referred to as the control stripe) was observed when urinary trypsinogen-2 concentration was within the normal range. The appearance of the control stripe confirmed the accuracy of the assay, while no blue stripes on the test strip suggested an erroneous test, in which case the test should be repeated.

Hyperamylasemia was defined as an increase of serum amylase of greater than the upper limit of normal $(82$
U/L).

Hyperlipasemia was defined as an increase of serum lipase of greater than the upper limit of normal $(60 \mathrm{U} / \mathrm{L})$.

Acute pancreatitis was diagnosed by abdominal pain persistent for at least 24 hours, associated with serum amylase and lipase equal to or greater than three times the upper normal limit [4].

Abdominal ultrasonography was done for all patients with special emphasis on the pancreas and biliary system to establish the presence of biliary obstruction and to diagnose its cause.

ERCP: The examination was done by using Olympus duodenoscope video system Lucera CV 260SC or using the Pentax lateral view endoscope ED-3440T and ED$3485 \mathrm{~T}$.

The contrast material used was urograffin. The cannulation of the ductal system was done under X-Ray screening to show the cause, the level and site of obstruction. Precut sphincterotomy was performed if cannulation was difficult All patients were monitored at least for six hours after the procedure to detect symptoms and signs of complications (e.g. tachycardia, hypotension, fever, vomiting and abdominal pain). Measurement of serum amylase and lipase was done as mentioned by sampling of blood at six hours post-ERCP. Urine sample was taken 6 hours post ERCP for Trypsinogen-2 determination by UT2DST. Patients were then either hospitalized or followed up.

\subsection{Statistical Analysis}

Data were statistically described in terms of mean and standard deviation (SD), frequencies (number of cases) and percentages when appropriate. Comparison of quantitative variables between the study groups was done using t-student test for parametric data or Mann Whitney $U$ test for non-parametric data in independent sam ples. For comparing categorical data, Fischer's exact test was performed when appropriate. A probability value ( $\mathrm{P}$ value) less than 0.05 was considered statistically significant. Kappa was used for the agreement. All statistical calculations were done using SPSS (Statistical Package for the Social Science; SPSS Inc., Chicago, IL, USA) version 15 for Microsoft Windows.

\section{RESULTS}

The study included 37 patients referred to the gastrointestinal endoscopy unit, Kasr El Aini hospital to perform ERCP. The age of the patients ranged between 22 and 77 years with a mean of $50 \pm 1$ years. Those patients were 23 males (62\%) and 14 females (38\%). From the 37 patients, 6 of them developed pancreatitis post ERCP (16.2\%) (3 males and 3 females) while 31 of them did not $(83.8 \%)$ as shown in Figure 1. 
No significant differences were seen between the two groups of patients (non pancreatitis group and pancreatitis group) as regard symptoms, signs, ultrasound and ERCP findings. The laboratory results of the studied patients showed that there are no significant differences between both groups of patients except for the lipase and amylase serum levels after ERCP (post lipase and post amylase) $(\mathrm{P}=0.000)$ for both of them (Table 1$)$.

The UT2DST before ERCP (pre_UT2DST) was negative in all studied patients.

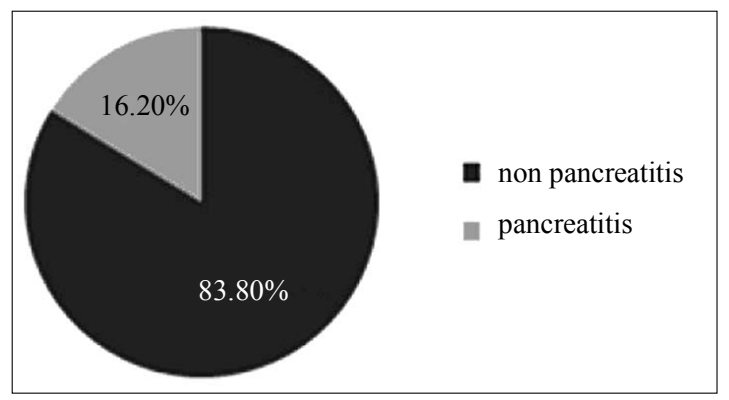

Figure 1. percentage of pancreatitis in the studied group.

Table 1. laboratory results of the 2 studied groups.

\begin{tabular}{|c|c|c|c|}
\hline & $\begin{array}{l}\text { Non pancreatitis } \\
\qquad \mathrm{N}=31\end{array}$ & $\begin{array}{c}\text { Pancreatitis } \\
\qquad N=6\end{array}$ & \multirow[t]{2}{*}{$P$ value } \\
\hline & Mean $\pm \mathrm{SD}$ & Mean $\pm \mathrm{SD}$ & \\
\hline $\mathrm{Hb}(\mathrm{gm} / \mathrm{dl})$ & $12.171 \pm 2.29$ & $11.717 \pm 1.95$ & 0.654 \\
\hline WBCx 1000 & $6.2 \pm 5$ & $8.300 \pm 4.5$ & 0.32 \\
\hline Plateletsx 1000 & $232.65 \pm 132.92$ & $326.80 \pm 217.855$ & 0.396 \\
\hline Bil.T (mg/dl) & $8.080 \pm 10.1$ & $5.350 \pm 20.6$ & 0.92 \\
\hline Bil.D (mg/dl) & $5.000 \pm 6.5$ & $3.500 \pm 13.8$ & 0.76 \\
\hline AST (U/L) & $75.00 \pm 56$ & $62.00 \mathrm{~b} \pm 254$ & 0.83 \\
\hline ALT (U/L) & $56.00 \pm 71$ & $55.00 \pm 293$ & 1.0 \\
\hline GGT (U/L) & $283.19 \mathrm{v} \pm 197.389$ & $282.33 \pm 135.848$ & 0.992 \\
\hline ALK.Ph (U/L) & $335.00 \pm 260$ & $325.0 \pm 334$ & 0.95 \\
\hline Urea (mg/dl) & $31.52 \pm 11.304$ & $30.83 \pm 15.171$ & 0.899 \\
\hline $\begin{array}{l}\text { Creatinine } \\
(\mathrm{mg} / \mathrm{dl})\end{array}$ & $0.892 \pm 0.3032$ & $1.017 \pm 0.2137$ & 0.345 \\
\hline $\begin{array}{l}\text { Pre_lipase } \\
(\bar{U} / \mathrm{L})\end{array}$ & $27.9 \pm 16.6$ & $24.1 \pm 5.3$ & 0.591 \\
\hline$\underset{(\mathrm{U} / \mathrm{L})}{\text { Pre_amylase }}$ & $67.1 \pm 29.5$ & $119.3 \pm 65.3$ & 0.109 \\
\hline $\begin{array}{l}\text { Post_lipase } \\
(\bar{U} / \mathrm{L})\end{array}$ & $28.9 \pm 14.7$ & $260.5 \pm 52.8$ & 0.000 \\
\hline $\begin{array}{l}\text { Post_amylsae } \\
(\mathrm{U} / \mathrm{L})\end{array}$ & $102.9 \pm 165.8$ & $1314.3 \pm 379.8$ & 0.000 \\
\hline
\end{tabular}

Post ERCP UT2DST was negative in 30 patients of the non pancreatitis group $(96.8 \%)$ and positive in one of them (3.2\%) (Table 2).

The test was positive in all patients with Pancreatitis $(100 \%)$. The sensitivity of the post ERCP UT2DST was $100 \%$ the Specificity was $97 \%$ with PPV $86 \%$, NPV $100 \%$ and the $\mathrm{P}$ value was $<0.01$.

Comparison between serum lipase and amylase levels post ERCP in relation to UT2DST test shows that positive UT2DST test was significantly associated with higher amylase and lipase serum levels after ERCP (post amylase and post lipase) as shown in Table $3(\mathrm{P}<0.01)$.

Post_UT2DST was positive when lipase $>130 \mathrm{U} / \mathrm{L}$ with sensitivity $86 \%$, specificity $100 \%$, AUC (Area under curve) $0.914, \mathrm{P}<0.01$. Post_UT2DST was positive when amylase $>122 \mathrm{U} / \mathrm{L}$ with sensitivity $100 \%$, specificity 90\%, AUC 0.981, $\mathrm{P}<0.01$ (Figure 2).

Assessment of post serum lipase level at cutoff 130 $\mathrm{U} / \mathrm{L}$ in relation to final diagnosis revealed that the sensitivity, PPV, specificity and NPV all were 100\% (Table 4).

Assessment of post serum amylase level at cutoff 122 $\mathrm{U} / \mathrm{L}$ in relation to final diagnosis revealed that the Sensitivity $=100 \%$, PPV $=60 \%$, specificity $=87 \%$ and NPV $=100 \%$ (Table 5).

Agreement of post_UT2DST and post serum lipase level at cutoff $130 \mathrm{U} / \mathrm{L}$ showed that the Kappa $=0.91(\mathrm{P}$ $<0.01)$. While agreement of Post_UT2DST and post serum amylase level at cutoff $122 \mathrm{U} / \mathrm{L}$ showed that the Kappa $0.77(\mathrm{P}<0.01)$.

\section{DISCUSSION}

This study was performed on 37 adult patients indicated

Table 2. Post ERCP UT2DST.

\begin{tabular}{ccccc}
\hline & & $\begin{array}{c}\text { Non pancreatitis } \\
\mathrm{N}=31\end{array}$ & $\begin{array}{c}\text { Pancreatitis } \\
\mathrm{N}=6\end{array}$ & $\begin{array}{c}\text { Total } \\
\mathrm{N}=37\end{array}$ \\
\hline $\begin{array}{c}\text { Post } \\
\text { UT2DST }\end{array}$ & Neg Count & 30 & 0 & 30 \\
& Pos Count & 1 & 6 & 7 \\
\hline
\end{tabular}

$\mathrm{P}<0.01$.

Table 3. Comparison between serum lipase and amylase post ERCP in relation to UT2DST.

\begin{tabular}{cccc}
\hline & Positive UT2DST & Negative UT2DST & \\
& $\mathrm{N}=7$ & $\mathrm{~N}=30$ & P value \\
& Mean \pm SD. & Mean \pm SD. & \\
\hline Pre_lipase (U/L) & $22.5 \pm 6.4$ & $28.4 \pm 0.67$ & 0.58 \\
Pre_amylase (U/L) & $121.1 \pm 59.8$ & $64.9 \pm 27.4$ & 0.06 \\
Post_lipase (U/L) & $226.3 \pm 102.5$ & $29.1 \pm 14.9$ & $<0.01$ \\
Post_amylsae (U/L) & $1144.1 \pm 568.3$ & $102.3 \pm 168.6$ & $<0.01$ \\
\hline
\end{tabular}




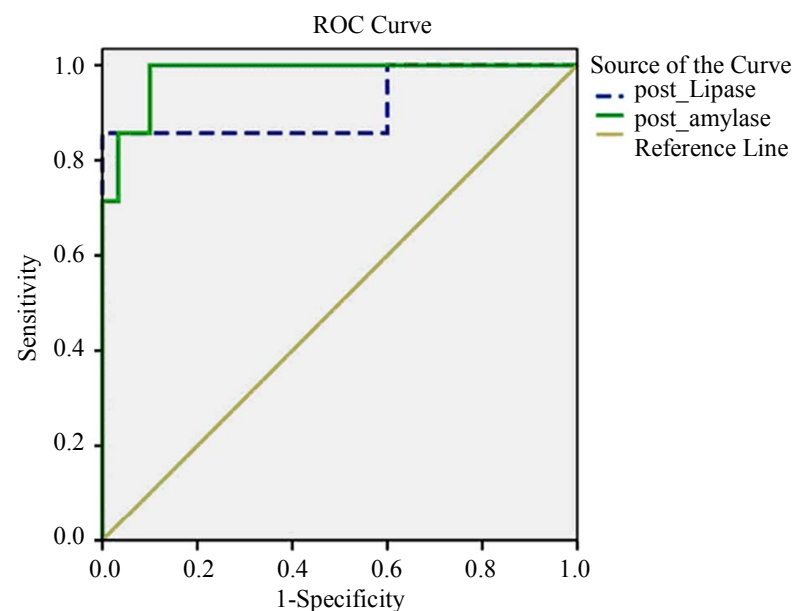

Figure 2. ROC curve for serum amylase and lipase levels post ERCP vs. results of post UT2DST test.

Table 4. Assessment of post serum lipase level at cutoff 130 in relation to final diagnosis.

\begin{tabular}{ccccc}
\hline & & $\begin{array}{c}\text { Non pancreatitis } \\
\mathrm{n}=31\end{array}$ & $\begin{array}{c}\text { Pancreatitis } \\
\mathrm{n}=6\end{array}$ & Total \\
\hline Post_lipase & $<130 \mathrm{U} / \mathrm{L}$ Count & 31 & 0 & 31 \\
$>130 \mathrm{U} / \mathrm{L}$ Count & 0 & 6 & 6 \\
\hline
\end{tabular}

Table 5. Assessment of post serum amylase level at cutoff 122 in relation to final diagnosis.

\begin{tabular}{ccccc}
\hline & $\begin{array}{c}\text { Non pancreatitis } \\
(\mathrm{n}=31)\end{array}$ & $\begin{array}{c}\text { Pancreatitis } \\
(\mathrm{n}=6)\end{array}$ & Total \\
\hline Post_amylase & $<122 \mathrm{U} / \mathrm{L}$ Count & 27 & 0 & 27 \\
& $>122 \mathrm{U} / \mathrm{L}$ Count & 4 & 6 & 10 \\
\hline
\end{tabular}

for ERCP, their ages ranged between 22 and 77 years with a mean $\pm \mathrm{SD}$ of $50 \pm 1$ years. Upon studying the patients after ERCP, from the 37 patients 6 of them developed pancreatitis post ERCP (16.2\%) while 31 of them did not (83.8\%).

The percentage of post ERCP pancreatitis in our study agreed with other studies like Murray et al., (2003) [7] which was $15.5 \%$, Sankaralingam et al., (2007) [2] which was 16\% and Kobayashi et al., 2011 [1] which was $12 \%$.

Safwat et al., (2011) [8] performed a study in Egypt and found that the overall incidence of post ERCP pancreatitis in their study was (14\%), which agreed with the percentage of post ERCP pancreatitis in our study.

The percentage of clinically detectable acute pancreastitis (AP) after ERCP ranges from 0 to $39 \%$ [9]. This variability in the reported rates of post ERCP pancreatitis is attributed to differences in criteria used for diagnosis, differences in patient populations, endoscopic techniques used, number of cases, aetiology and endoscopic experience [10].

The higher rates of pancreatitis in our study above the rates reported in some studies may be attributed to more strict parameters used for diagnosis in those studies. In our study we used threefold elevation of amylase level as a marker for diagnosis of acute pancreatitis. Other studies as that done by Testoni and Bagnolo, (2001) [11] revealed that the frequency of post-ERCP/sphincterotomy pancreatitis was between $1.3 \%$ and $7.6 \%$ and Freeman et al., (2001) [12] found that the frequency of postERCP pancreatitis that occurred was $(6.7 \%)$, both of them used higher levels of serum amylase (five folds elevation) as a diagnostic marker for pancreatitis.

The Actim Pancreatitis MedixBiomedica urine test strip measures concentrations of urinary trypsinogen-2 with a detection limit of the test of approximately 50 $\mu \mathrm{g} / \mathrm{L}$. It has been shown that the results from a urinary trypsinogen-2 test strip agrees well with the rise in serum trypsinogen-2 for a diagnosis of post-ERCP pancreatitis, but the urine dip stick cannot be used to assess the severity of pancreatitis because it is not a quantitative measurement [13].

In our study, 6 of the 37 patients developed post ERCP pancreatitis (PEP), all of them had positive post ERCP Urinary Trypsinogen-2-Dipstick test (UT2DST) with a Sensitivity $100 \%$, Specificity 97\%, PPV $86 \%$, NPV $100 \%$ and the $\mathrm{P}$ value was $<0.01$.

Kemppainen et al., (1997) [13] tested 106 patients undergoing ERCP with a urinary trypsinogen-2 test strip 6 hours after ERCP, in whom 11 patients (10.4\%) developed post-ERCP pancreatitis, they showed that the sensitivity and specificity of urinary trypsinogen-2 strip test in diagnosing post-ERCP pancreatitis were $81 \%$ and $97 \%$, respectively.

The high negative predictive value $(98 \%)$ supported the clinical value in excluding the development of postERCP pancreatitis.

In another small-scale study, Sankaralingam et al., (2007) [2] tested 30 patients undergoing ERCP with urinary trypsinogen- 2 test strip at 1 and 4 hours after ERCP, in whom 5 patients $(17.2 \%)$ developed post-ERCP pancreatitis, they demonstrated that urinary trypsinogen-2 test had $100 \%$ sensitivity and negative predictive value at 1 and 4 hours after ERCP. The specificities at 1 and 4 hours after ERCP were $91 \%$ and $96 \%$, respectively.

Tseng et al., (2011) [14] examined 150 patients undergoing ERCP with urinary trypsinogen-2 test strip before and 3 hours after ERCP, in whom 13 (8.7\%) patients developed post-ERCP pancreatitis, urinary trypsinogen-2 strip test at 3 hours after ERCP had high sensitivity $(84.6 \%)$, specificity $(97.1 \%)$, and negative predictive value $(98.5 \%)$ that are compatible also with the report of Kemppainen et al., (1997) [13]. 
Another study reported that urinary trypsinogen-2 had a 94\% sensitivity for diagnosing acute pancreatitis [6], Hedstrom et al., (1996) [15] also reported that the level of trypsinogen-2 correlated with the severity of acute pancreatitis.

Serum levels of amylase and lipase were examined at 6 hours after ERCP procedure in our study. We found that the elevations of serum lipase have high negative and positive predictive values which were both $(100 \%)$, the negative predictive value for the serum amylase was $(100 \%)$ but the positive predictive value was $(60 \%)$ which was lower than that of urinary trypsinogen-2 strip test $(86 \%)$, and there was a significant difference between levels of post ERCP amylase and lipase in both groups.

Tseng et al., (2011) [14] examined the serum levels of amylase and lipase at 3 hours after ERCP procedure and found that the elevations of serum amylase or lipase ( 3 or 5 times normal) have high negative predictive values (94.8\% - 99.1\%); however, their positive predictive values $(36.4 \%-42.9 \%)$ were markedly lower than that of urinary trypsinogen-2 strip test (73.3\%).

Our data showed a significantly higher mean level of serum amylase 6 hours after ERCP in the pancreatitis group $(1314.3 \pm 379.8 \mathrm{U} / \mathrm{L})$ relative to the non pancreatitis group $(102.9 \pm 165.8 \mathrm{U} / \mathrm{L})$ which agreed with the Kobayashi et al., (2011) [1] study which showed that the mean level of amylase 2 hours after ERCP in the pancreatitis group was $(969.6 \pm 220.4 \mathrm{U} / \mathrm{L})$ relative to the healthy group which was $(120.4 \pm 13.5 \mathrm{U} / \mathrm{L})$.

However, in our study 4 of 31 cases of non-pancreatitis showed elevated serum levels of the amylase. In previous reports, post-ERCP levels of pancreatic enzymes in cases with non pancreatitis peaked 6 hours after ERCP, Kobayashi et al., 2011 [1] found that 14 of 60 cases of non pancreatitis group showed greater than 3-fold elevation in amylase levels.

This may be due to the mechanics of the endoscopy procedure which can cause enzymes to be reabsorbed from the digestive tract via several mechanisms, salivary gland stimulation associated with the insertion of a mouthpiece or endoscope, insertion of a scope into the gastrointestinal tract or introduction of air into the gastrointestinal tract [1].

Post-ERCP hyperamylasemia is reported by many authors to be extremely common reaching up to $70 \%[16$, 17].

The finding of post ERCP hyperamylasemia may be attributed to other maneuvers used during ERCP as manipulation of the papilla during difficult cannulation, pancreatic duct cannulation or injection, precut sphincterotomy, balloon dilatation and extraction of large stones. The mechanical trauma to the papilla or pancreatic sphincter during instrumentation may cause transient obstruction of outflow of pancreatic juice. Also, subjecting the pancreatic duct to a sudden increase in pressure may be the cause of post ERCP hyperamylasemia. Passage of common bile duct stones is also known to cause hyperamylasemia [18].

In conclusion, the urinary trypsinogen-2 dipstick test can be used as an easy and rapid test for early diagnosis of post-ERCP pancreatitis with high sensitivity and specificity and can help clinicians to provide intensive care and possible medical treatment as early as possible.

\section{REFERENCES}

[1] Kobayashi, K., Sasaki, T., Serikawa, M., Inoue, M., Itsuki, H. and Chayama, K. (2011) Assessment of trypsinogen-2 levels as an early diagnostic marker for post endoscopic retrograde cholangio-pancreatography pancreatitis. Pancreas, 40, 1206-1210.

http://dx.doi.org/10.1097/MPA.0b013e318223d362

[2] Sankaralingam, S., Wesen, C., Barawi, M., Galera, R. and Lloyd, L. (2007) Use of the urinary trypsinogen-2 dip stick test in early diagnosis of pancreatitis after endoscopic retrograde cholangiopancreatography. Surgical Endoscopy, 21, 1312-1315. http://dx.doi.org/10.1007/s00464-006-9099-2

[3] Chen, C.C., Wang, S.S., Lu, R.H., Lu, C.C., Chang, F.Y. and Lee, S.D. (2003) The early changes of serum proinflammatory and anti-inflammatory cytokines after endoscopic retrograde cholangiopancreatography. Pancreas, 26, 375-380.

http://dx.doi.org/10.1097/00006676-200305000-00011

[4] Ito, K., Fujita, N., Noda, Y., Kobayashi, G., Horaguchi, J., Takasawa, O. and Obana, T. (2007) Relationship between post-ERCP pancreatitis and the change of serum amylase level after the procedure. World Journal of Gastroenterology, 13, 3855-3860.

[5] Chang, K., Lu, W., Zhang, K., Jia, S., Li, F., Wang, F., Deng, S. and Chen, M. (2012) Rapid urinary trypsinogen-2 test in the early diagnosis of acute pancreatitis: A meta-analysis. Clinical Biochemistry, 45, 1051-1056. http://dx.doi.org/10.1016/j.clinbiochem.2012.04.028

[6] Kemppainen, E.A., Hedström, J.I., Puolakkainen, P.A., Sainio, V.S., Haapiainen, R.K., Perhoniemi, V., Osman, S., Kivilaakso, E.O. and Stenman, U.H. (1997) Rapid measurement of urinary trypsinogen-2 as a screening test for acute pancreatitis. New England Journal of Medicine, 336, 1788-1793. http://dx.doi.org/10.1056/NEJM199706193362504

[7] Murray, B., Carter, R., Imrie, C., Evans, S. and O'Suilleabhain, C. (2003) Diclofenac reduces the incidence of acute pancreatitis after endoscopic retrograde cholangiopancreatography. Gastroenterology, 124, 1786-1791. http://dx.doi.org/10.1016/S0016-5085(03)00384-6

[8] Safwat, W., Anas, A., Abdel Raouf, E., Abdel Aziz, A. and Abu EL-Ezz, M. (2011) Incidence of pancreatitis in failed versus successful ERCP and the possible benefit of pancreatic duct stenting in high risk cases. Prospective randomized study. New York Science Journal, 4, 29-32. 
[9] Sherman, S. and Lehman, G.A. (1991) ERCP- and endoscopic sphincterotomy-induced pancreatitis. Pancreas, 6, 350-367. http://dx.doi.org/10.1097/00006676-199105000-00013

[10] Andriulli, A., Loperfido, S., Napolitano, G., Niro, G., Valvano, M.R., Spirito, F., Pilotto, A. and Forlano, R. (2007) Incidence rate of post-ERCP complications: A systematic survey of prospective studies. American Journal of Gastroenterology, 102, 1781-1788. http://dx.doi.org/10.1111/j.1572-0241.2007.01279.x

[11] Testoni, P.A. and Bagnolo, F. (2001) Pain at 24 hours associated with amylase levels greater than 5 times the upper normal limit as the most reliable indicator of postERCP pancreatitis. Gastrointestinal Endoscopy, 53, 3339. http://dx.doi.org/10.1067/mge.2001.111390

[12] Freeman, M.L., DiSario, J.A., Nelson, D.B., Fennerty, M.B., Lee, J.G., Bjorkman, D.J., Overby, C.S., Aas, J., Ryan, M.E., Bochna, G.S., Shaw, M.J., Snady, H.W., Erickson, R.V., Moore, J.P. and Roel, J.P. (2001) Risk factors for post-ERCP pancreatitis, a prospective, multicenter study. Gastrointestinal Endoscopy, 54, 425-434. http://dx.doi.org/10.1067/mge.2001.117550

[13] Kemppainen, E., Hedström, J., Puolakkainen, P., Halttunen, J., Sainio, V., Haapiainen, R. and Stenman, U.H. (1997) Urinary trypsinogen-2 test strip in detecting ERCPinduced pancreatitis. Endoscopy, 29, 247-251. http://dx.doi.org/10.1055/s-2007-1004184

[14] Tseng, C.W., Chen, C.C., Lin, S.Z., Chang, F.Y., Lin, H.C. and Lee, S.D. (2011) Rapid urinary trypsinogen-2 test strip in the diagnosis of pancreatitis after endoscopic retrograde cholangiopancreatography. Pancreas, 40, 12111214. http://dx.doi.org/10.1097/MPA.0b013e31821fcdcf

[15] Hedström, J., Korvuo, A., Kenkimäki, P., Tikanoja, S., Haapiainen, R., Kivilaakso, E. and Stenman, U.H. (1996) Urinary trypsinogen-2 test strip for acute pancreatitis. Lancet, 347, 729-730. http://dx.doi.org/10.1016/S0140-6736(96)90078-1

[16] Chen, Y.K. and Pleskow, D.K. (2007) SpyGlass singleoperator peroralcholangiopancreatoscopy system for the diagnosis and therapy of bile-duct disorders: A clinical feasibility study (with video). Gastrointestinal Endoscopy, 65, 832-841. http://dx.doi.org/10.1016/j.gie.2007.01.025

[17] Jaik, N.P., Hoey, B.A. and Stawicki, S.P. (2008) Evolving role of endoscopic retrograde cholangiopancreatography in management of extrahepatic hepatic ductal injuries due to blunt trauma: Diagnostic and treatment algorithms. HPB Surgery, 2008, Article ID: 259141.

[18] Freeman, M.L. (2002) Adverse outcomes of ERCP. Gastrointestinal Endoscopy 56, S273-S282. http://dx.doi.org/10.1016/S0016-5107(02)70025-4 